\title{
J. B. S. Haldane: an isolated souvenir
}

\author{
P. P. DIVAKARAN* \\ Riviera Retreat, Thevara Ferry Road, Kochi 682 013, India \\ *E-mail: ppdppd@gmail.com.
}

Published online 24 November 2017

Keywords. Indian Science Congress; Tata Institute of Fundamental Research; independent India.

I never met Haldane. That is not surprising since, genetically speaking, I am illiterate. But I saw him once in performance (no other word will do), at the Indian Science Congress of 1960 in Bombay (as it then was). The performance left an unforgettable memory: partly because of the times - the glow of our newly-won independence was still upon us and here was a famous British scientist wishing to help turn our dreams into reality; partly it was on account of my impressionable age; but mostly it was down to Haldane's own extraordinarily communicative personality.

The 1960 Science Congress was a remarkable event. Among the luminaries who came from abroad-Haldane did not quite qualify as he was already in Calcutta - the ones I remember are Niels Bohr, Theodosius Dobzhansky and a youthful and very impressive Abdus Salam. There were the usual public lectures (at the Oval, in the shadow of the Rajabai Tower), of high scientific quality and, in Haldane's case, of equal entertainment value. It was of course the entertainment that stayed in the memory; at one point, while holding forth on the benefits of a rational approach to activities of daily life, he launched into an attack on the sari as the default garment of working Indian women, complete with a graphic demonstration of a sari-clad woman trying to escape from a chasing bull by climbing over a fence (he was himself dressed in white kurta-pyjama). Dobzhansky who was sharing the stage [I think it was] was greatly amused as was the large audience.

Haldane's more serious message was about why and how India must break away from the mindset of the colonized and cultivate science in its own interest and by its own genius. The message resonated strongly with us: a few students from the Tata Institute of Fundamental Research who had walked the short distance from the Old Yacht Club-TIFR had not yet moved to its new campus at the southern tip of Colaba-looking for reassurance that we had not made a mistake in choosing a vocation in science. TIFR itself was an amazingly stimulating place then and the inspiration came as much from other young people like us, some of whom were already producing research of the highest quality, as from our senior mentors with Homi Bhabha at the head; they were able to persuade the very best in their fields to undertake long visits to India and lecture to us. Both Bohr and Salam gave lectures at TIFR during their Science Congress visit. Salam's, on the pioneering Yang-Mills paper on non-Abelian gauge theory, had such an impact that the first ever application of the theory to a problem in particle physics came out of TIFR, just before the better known work of Sakurai.

It is perhaps natural that this short note which began with one particular memory of Haldane has transmuted into a recollection of what it was like to be growing up scientifically in India in the late 1950s and early 1960s. It was a time of great expectations and Haldane's adoption of India as his home fitted in well with that optimism. Those of us just starting out in a life of science in India knew, even if somewhat indistinctly, that we were privileged. The scientific landscape has changed greatly since and the change has not always been in a particularly 'Indian' direction. Nevertheless, I think Haldane would have approved. 